\title{
Increased intracellular calcium mobilization in platelets from patients with Type 2 (non-insulin-dependent) diabetes mellitus
}

\author{
H. Ishii, F. Umeda, T. Hashimoto and H. Nawata \\ 3rd Department of Internal Medicine, Faculty of Medicine, Kyushu University, Fukuoka, Japan
}

Summary. Enhanced platelet functions have been reported in patients with diabetes mellitus. Our recent study demonstrated that phosphoinositide turnover is increased in platelets from diabetic patients. In the present study, we evaluated the abnormality in platelet intracellular calcium mobilization in patients with Type 2 (non-insulin-dependent) diabetes mellitus using fura-2, a fluorescent calcium indicator. Washed platelets were prepared from six diabetic patients with increased platelet aggregation rates (DM-A group), seven diabetic patients with normal platelet aggregation rates (DM-B group), and eight age-matched healthy control subjects. The basal intracellular free calcium concentrations in platelets were similar among the three groups. Thrombin $(0.025-0.1 \mathrm{U} / \mathrm{ml})$ induced a dose-dependent increase in intracellular calcium in both the presence and the absence of extracellular calcium. This increase in the presence of extracellular calcium, which depends on calcium influx and release, was significantly higher in the DM-A group than in the DM-B and control groups. However, there was no significant difference between the control group and the DM-B group. In the absence of extracellular calcium, thrombin-induced calcium increase, which depends only on calcium release, was also significantly enhanced in the DM-A group. Furthermore, the calcium increase stimulated by platelet-activating factor $(10 \mathrm{nmol} / 1)$ with and without extracellular calcium was significantly higher in the DM-A group than in the other groups. Additionally, calcium ionophore A23187 (100 nmol/l) caused a significantly higher calcium increase in the DM-A group with extracellular calcium, while the calcium increase without extracellular calcium showed no significant difference among the three groups. These observations suggest that enhanced intracellular calcium mobilization due to increased calcium influx and release may be closely related to platelet hyperfunctions in diabetes mellitus.

Key words: Calcium, platelet, diabetes mellitus, thrombin, platelet-activating factor, A23187.
Enhanced platelet functions have been demonstrated in subjects with diabetes mellitus. These platelet hyperfunctions involve increased platelet adhesiveness and aggregation, serotonin secretion, and prostaglandin synthesis in response to adenosine diphosphate, collagen, thrombin, and platelet-activating factor (PAF) in both platelet-rich plasma and washed platelet suspension [1-5]. However, there have been few studies on the abnormalities in platelet intracellular signal transduction in patients with diabetes mellitus.

Intracellular free calcium plays a major role in platelet signal transduction and causes platelet shape change [6,7], aggregation [8], release of intracellular granules $[9,10]$, and prostaglandin synthesis [11]. Phosphoinositide breakdown generates inositol 1,4,5-trisphosphate [12] which induces calcium release from intracellular calcium pools [13]. Our recent study [14] demonstrated that phosphoinositide turnover is increased in platelets obtained from diabetic patients. Therefore, the possibility that platelet intracellular calcium mobilization is altered in diabetes mellitus may arise. In the present study, we measured platelet intracellular free calcium concentrations $\left(\left[\mathrm{Ca}^{2+}\right] \mathrm{i}\right)$ in patients with Type 2 (non-insulin-dependent) diabetes mellitus under basal conditions and following stimulation by thrombin, $\mathrm{PAF}$ and calcium ionophore, A23187 using a fluorescent calcium indicator fura-2.

\section{Subjects and methods}

\section{Subjects}

Thirteen patients with Type 2 diabetes and eight age- and sexmatched healthy control subjects were selected for the present study. Neither the control subjects nor the Type 2 diabetes patients had taken any antiplatelet agents such as aspirin for at least two weeks 
Table 1. Clinical characteristics of the subjects

\begin{tabular}{|c|c|c|c|}
\hline & $\begin{array}{l}\text { Control subjects } \\
(n=8)\end{array}$ & $\mathrm{DM}-\mathrm{A}(n=6)$ & DM-B $(n=7)$ \\
\hline $\begin{array}{l}\text { Numbers } \\
\text { Sex (M/F) } \\
\text { Therapy (insulin/drug/diet) }\end{array}$ & $4 / 4$ & $\begin{array}{l}3 / 3 \\
1 / 2 / 3\end{array}$ & $\begin{array}{l}4 / 3 \\
2 / 2 / 3\end{array}$ \\
\hline $\begin{array}{l}\text { Age (year) } \\
\text { BMI }\left(\mathrm{kg} / \mathrm{m}^{2}\right) \\
\text { Duration of diabetes (year) } \\
\text { Fasting blood glucose (mmol/l) } \\
\mathrm{HbA}_{1 \mathrm{c}}(\%) \\
\text { Platelet aggregation rate }(\%)^{\mathrm{b}}\end{array}$ & $\begin{array}{r}51.3 \pm 3.5 \\
21.9 \pm 1.5 \\
4.9 \pm 1.0 \\
38.5 \pm 2.2\end{array}$ & $\begin{aligned} & 53.2 \pm 3.1 \\
& 22.6 \pm 2.1 \\
& 9.0 \pm 3.5 \\
& 13.7 \pm 1.4^{\mathrm{c}} \\
& 11.2 \pm 0.8 \\
& 63.9 \pm 3.7^{\mathrm{c}, \mathrm{d}}\end{aligned}$ & $\begin{aligned} 50.9 & \pm 7.9 \\
23.1 & \pm 2.2 \\
8.1 & \pm 1.9 \\
11.7 & \pm 1.5^{\mathrm{c}} \\
9.5 & \pm 0.4 \\
35.0 & \pm 4.5\end{aligned}$ \\
\hline $\begin{array}{l}\text { Values are means } \pm \text { SEM. } \\
\text { Only glibenclamide was used a } \\
\text { normal laboratory range: } 18.6- \\
{ }^{2} p<0,01 \text { vs control group; } \\
p<0.01 \text { v DM-B group. } \\
\text { DM-A = Diabetic patients with } \\
\text { DM-B }=\text { Diabetic patients with } n\end{array}$ & $\begin{array}{l}\text { ral hypoglycaemi } \\
6 \\
\text { sed platelet aggre } \\
\text { i platelet aggrega }\end{array}$ & $\begin{array}{l}\text { Igent; } \\
\text { tion rates; } \\
\text { n rates }\end{array}$ & . \\
\hline
\end{tabular}

before the study. The patients with Type 2 diabetes were divided into two experimental groups, DM-A group and DM-B group, on the basis of platelet aggregation rate induced by $0.3 \mathrm{U} / \mathrm{ml}$ of human. thrombin. The DM-A group included the diabetic patients with platelet aggregation rates over $46.4 \%$, which is the upper limit of the normal range of the platelet aggregation rate (mean $+2 \mathrm{SD})$ in our laboratory. The DM-B group included the patients with platelet aggregation rates less than $46.4 \%$. The clinical characteristics of the subjects are summarized in Table 1 . There were no significant differences in age, BMI, duration of diabetes, fasting blood glucose levels or $\mathrm{HbA}_{1 \mathrm{c}}$ levels between the DM-A group and the DM-B group.

\section{Platelet aggregation rate}

The platelet aggregation rate was determined as previously reported [4]. After overnight fasting, blood was drawn by venous puncture with sodium citrate at a final concentration of $12 \mathrm{mmol} / \mathrm{l}$. The blood sample was immediately centrifuged at $160 \times \mathrm{g}$ for $10 \mathrm{~min}$ to obtain platelet-rich plasma (PRP). The rest of the blood wasrecentrifuged at $1500 \times \mathrm{g}$ for $10 \mathrm{~min}$ to obtain platelet-poor plasma (PPP). The platelet count of PRP was adjusted to $2 \times 10^{8} \mathrm{cells} / \mathrm{ml}$ using autologous PPP. Platelet aggregation was achieved according to Born's turbidimetric method [15] with an Auto RAM-21 aggregometer (Rikadenki Kogyo Co. Ltd., Tokyo, Japan) and recorded with an electronic recorder R12 (Rikadenki Kogyo Co. Ltd.). Briefly, $250 \mu \mathrm{l}$ of PRP was stirred magnetically at $1,100 \mathrm{rev} / \mathrm{min}\left(37^{\circ} \mathrm{C}\right)$. After $1 \mathrm{~min}$ of pre-incubation, $0.3 \mathrm{U} / \mathrm{ml}$ of human thrombin (Sigma, St. Louis, Mo., USA) was added, and the change in light transmission was recorded. Assuming that the PPP tepresented $100 \%$ aggregation and the PRP represented $0 \%$ aggregation, the maximal aggregation within 1 min after the addition of thrombin was determined as the platelet aggregation rate.

\section{Measurement of $\left[\mathrm{Ca}^{2+}\right] \mathrm{i}$}

After overnight fasting, blood was drawn from the antecubital vein with acid citrate dextrose (one volume to six volumes of blood). PRP was obtained by centrifuging the blood at $160 \mathrm{xg}$ for $10 \mathrm{~min}$. The platelets in PRP were incubated with $2 \mu \mathrm{mol} / \mathrm{l}$ fura- 2 acetoxymethyl ester (Dojin Chemical Laboratory, Kumamoto, Japan), a fluorescent calcium indicator, for 30 min at $37^{\circ} \mathrm{C}$. The PRP was then centrifuged at $800 \mathrm{xg}$ for $10 \mathrm{~min}$, and the platelet pellet was suspended at $2 \times 10^{8}$ cells $/ \mathrm{ml}$ in calcium-free buffer $(135 \mathrm{mmol} / 1 \mathrm{NaCl}, 5 \mathrm{mmol} / \mathrm{K} \mathrm{KCl}$, $1 \mathrm{mmol} / / \mathrm{MgCl}_{2}, 5.5 \mathrm{mmol} / \mathrm{glucose}, 20 \mathrm{mmol} / \mathrm{lHEPES}, \mathrm{pH}$ 7.4). The extracellular calcium concentration was adjusted by adding $1 \mathrm{mmol} / \mathrm{l}$ $\mathrm{CaCl}_{2}$ for $5 \mathrm{~min}$ at $37^{\circ} \mathrm{C}$. This incubation time was chosen because calcium mobilization increased following the addition of $\mathrm{CaCl}_{2}$ and reached a stable level within 2-4 min which persisted for at least 30 min. Fura-2 fluorescence was measured with a spectrofluorophotometer RF-5000 (Shimadzu, Kyoto, Japan) in a thermostated $\left(37^{\circ} \mathrm{C}\right.$ ) quartz cuvette at $340 \mathrm{~nm}$ and $380 \mathrm{~nm}$ excitation wavelengths and a $500 \mathrm{~nm}$ emission wavelength. Platelets were then stimulated by addition of thrombin $(0.025-0.1 \mathrm{U} / \mathrm{ml})$, PAF (10 nmol/1; Sigma) or A23187 (100 nmol/l; Sigma), and the changes in fluorescence were continuously recorded. In parallel experiments, $5 \mathrm{mmol} / \mathrm{LETT}$ was added to platelet suspension containing $1 \mathrm{mmol} / \mathrm{CaCl}_{2}$ just before addition of each stimulant. The $\left[\mathrm{Ca}^{2+}\right] \mathrm{i}$ was calculated as described previously using a calcium/dye dissociation constant for fura-2 of $224 \mathrm{nmol} / 1[16]$.

\section{Statistical analysis}

To test for differences between the three groups, analysis of variance was used. If significant differences were found, Student's unpaired $t$ test was used for comparison between the groups. The correlations between changes in $\left[\mathrm{Ca}^{2+}\right] \mathrm{i}$ and epidemiological variables were evaluated by linear-regression analysis. All $p$ values less than 0.05 were accepted as statistically significant.

\section{Results}

There was no significant difference in platelet $\left[\mathrm{Ca}^{2+}\right] \mathrm{i}$ under basal conditions among the control group $(77 \pm 2 \mathrm{nmol} / 1$, mean $\pm \mathrm{SEM})$, the DM-A group $(75 \pm 2 \mathrm{nmol} / \mathrm{l})$, and the DM-B group $(79 \pm 2 \mathrm{nmol} / \mathrm{l})$. These basal $\left[\mathrm{Ca}^{2+}\right] \mathrm{i}$ values were greater than those in our recent report (about $100 \mathrm{nmol} / \mathrm{l}$ ) [14]. The difference of the $\left[\mathrm{Ca}^{2+}\right] \mathrm{i}$ may have resulted from the difference of platelet count between the studies $\left(2\right.$ and $5 \times 10^{8}$ cells $\left./ \mathrm{ml}\right)$. Stimulation by thrombin in the presence of extracellular calcium $(1 \mathrm{mmol} / \mathrm{l} \mathrm{CaCl})$ induced a rapid and marked increase in platelet $\left[\mathrm{Ca}^{2+}\right] \mathrm{i}$, which depends on calcium influx from extracellular space and calcium release from intracellular calcium pools. The $\left[\mathrm{Ca}^{2+}\right] \mathrm{i}$ reached a maximal level within 20-30 s after addition of thrombin (Fig. 1). By increasing the thrombin concentrations from 0.025 to $0.1 \mathrm{U} / \mathrm{ml}$, a dose-dependent increase in $\left[\mathrm{Ca}^{2+}\right] \mathrm{i}$ was observed in the control, DM-A, and DM-B groups. This $\left[\mathrm{Ca}^{2+}\right] \mathrm{i}$ increase was significantly higher in the DM-A group than in the DM-B group at all concentrations tested 

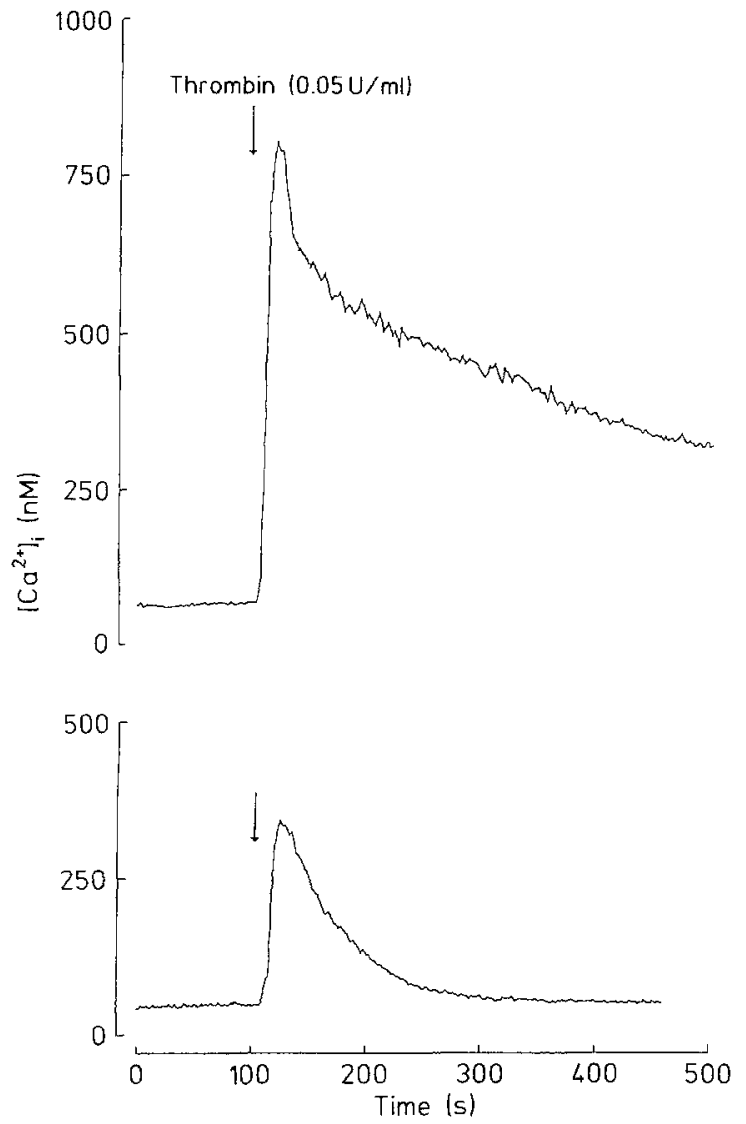

Fig. 1. Representative traces of changes in platelet intracellular free calcium concentrations $\left(\left[\mathrm{Ca}^{2} \div\right] \mathrm{i}\right)$ induced by thrombin. Fura-2-loaded washed platelets were stimulated with $0.05 \mathrm{U} / \mathrm{ml}$ of thrombin in the presence of $1 \mathrm{mmol} / \mathrm{l} \mathrm{CaCl}$ (top panel) or $5 \mathrm{mmol} / 1 \mathrm{EGTA}$ (bottom panel). Changes in fura-2 fluorescence intensity were recorded at $340 \mathrm{~nm}$ and $380 \mathrm{~nm}$ excitation wavelengths and a $500 \mathrm{~nm}$ emission wavelength. The $\left[\mathrm{Ca}^{2+}\right] \mathrm{i}$ was calculated using a calcium/dye dissociation constant for fura- 2 of $224 \mathrm{nmol} / 1$ [16]. The traces were observed in platelets from one of the diabetic subjects with increased platelet aggregation rate

and in the control group at all concentrations except for $0.05 \mathrm{U} / \mathrm{ml}$ (Fig. 2). However, there were no significant differences between the control group and the DM-B group. When thrombin was added in the presence of $5 \mathrm{mmol} / \mathrm{l}$ EGTA in order to reduce extracellular calcium to negligible concentration (approximately $14 \mathrm{nmol} / \mathrm{l}$ ), the platelet $\left[\mathrm{Ca}^{2+}\right] \mathrm{i}$ increase, which depends only on calcium release from intracellular pools, was rapid but much lower (Fig. 1). The $\left[\mathrm{Ca}^{2+}\right] \mathrm{i}$ increase in the DM-A group was also significantly higher than that in the control group at all concentrations tested except for $0.025 \mathrm{U} / \mathrm{ml}$ and that in the DM-B group except for $0.075 \mathrm{U} / \mathrm{ml}$ (Fig. 2).

Stimulation by PAF in the range of 2.5 to $200 \mathrm{nmol} / 1$ produced a dose-dependent increase in $\left[\mathrm{Ca}^{2+}\right]$ i with the maximal plateau observed at $10 \mathrm{nmol} / 1$. Therefore, we chose the concentration of $10 \mathrm{nmol} / \mathrm{l}$ for the subsequent stimulation studies by PAF. The $\left[\mathrm{Ca}^{2+}\right] \mathrm{i}$ increase induced by PAF was significantly higher in the DM-A group than in the other groups in both the presence and the absence of extracellular calcium (Fig.3). Finally, A23187 $(100 \mathrm{nmol} / \mathrm{l})$ also caused a significantly greater $\left[\mathrm{Ca}^{2+}\right] \mathrm{i}$ increase in the DM-A group than in the other groups in the
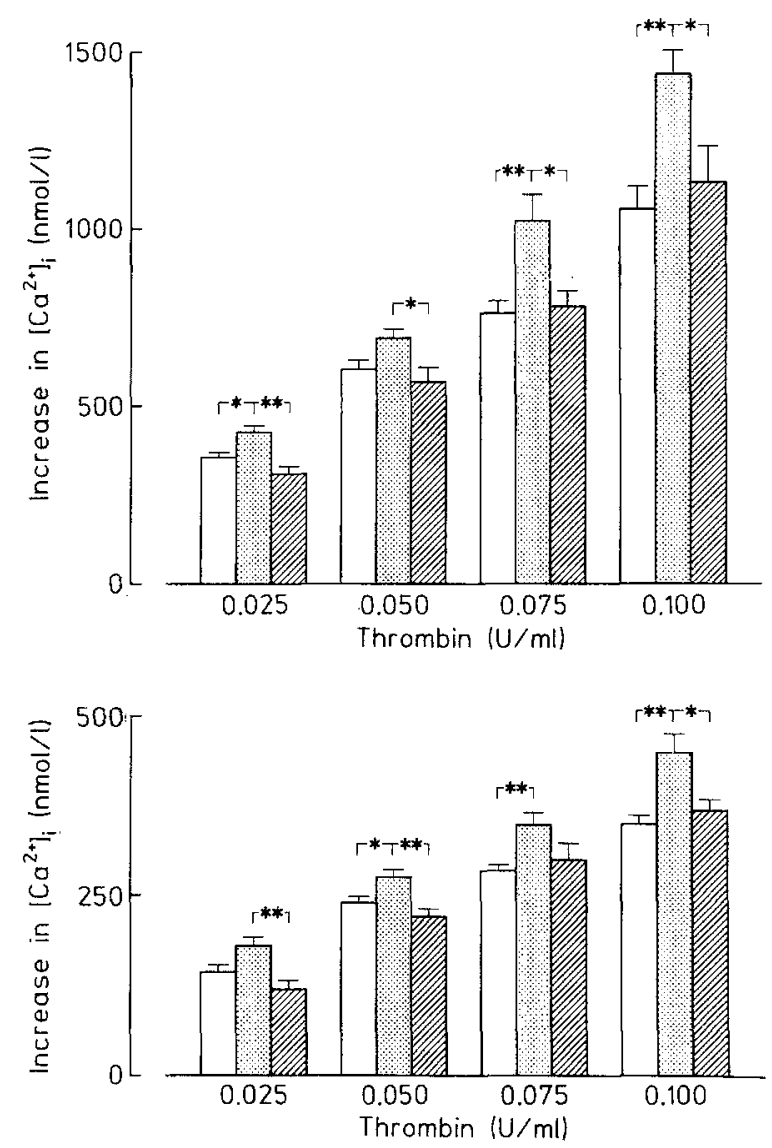

Fig. 2. Thrombin-induced increase in intracellular free calcium concentrations $\left(\left[\mathrm{Ca}^{2+}\right] \mathrm{i}\right.$ ) in the presence of $1 \mathrm{mmol} / \mathrm{CaCl}_{2}$ (top panel) or $5 \mathrm{mmol} / \mathrm{l}$ EGTA (bottom panel) in washed platelets from the control group ( $n=8$; open columns), the diabetic patients with increased platelet aggregation rates (DM-A) group $(n=6$; dotted columns), and the diabetic patients with normal platelet aggregation rates (DM-B) group ( $n=7$; hatched columns). The increase in $\left[\mathrm{Ca}^{2+}\right] \mathrm{i}$ was calculated by subtracting the basal $\left[\mathrm{Ca}^{2+}\right] \mathrm{i}$ from the maximal $\left[\mathrm{Ca}^{2+}\right] \mathrm{i}$ induced by thrombin. All experiments were performed in duplicate. Values are means \pm SEM. ${ }^{*} p<0.05{ }^{* *} p<0.01$

presence of extracellular calcium. However, in the absence of extracellular calcium, there was no significant difference among the three groups (Fig.4).

In addition, correlations were examined between the $\left[\mathrm{Ca}^{2+}\right] \mathrm{i}$ increase stimulated by thrombin, PAF, or A23187 and the epidemiological factors. However, there were no significant correlations between the $\left[\mathrm{Ca}^{2+}\right] \mathrm{i}$ increase and age, BMI, duration of diabetes, fasting blood glucose levels, or $\mathrm{HbA}_{1 \mathrm{c}}$ levels.

\section{Discussion}

In the present study, we measured platelet $\left[\mathrm{Ca}^{2+}\right] \mathrm{i}$ in the healthy control subjects, the Type 2 diabetic patients with increased platelet aggregation rates (DM-A group), and the Type 2 diabetic patients with normal platelet aggregation rates (DM-B group). Although basal $\left[\mathrm{Ca}^{2+}\right] \mathrm{i}$ values were similar among the three groups, stimulation by thrombin and PAF induced a significantly greater $\left[\mathrm{Ca}^{2+}\right] \mathrm{i}$ increase in the DM-A group than in the other groups, when the agonists were added in the absence of extracel- 


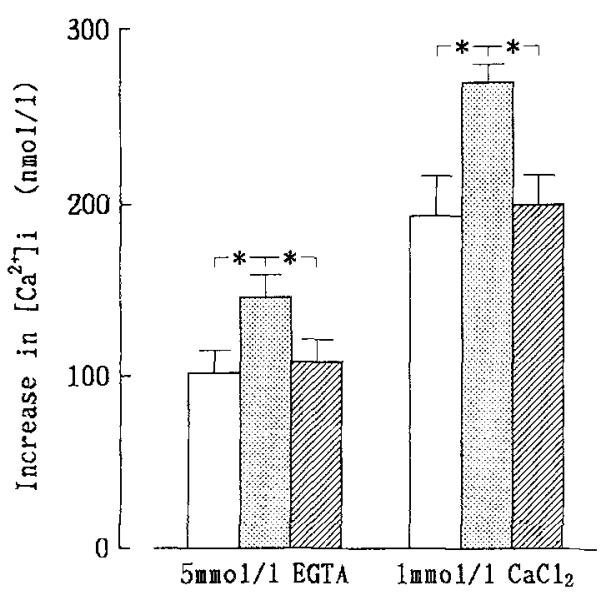

Fig.3. Platelet activating factor (PAF)-induced increase in intracellular free calcium concentrations $\left(\left[\mathrm{Ca}^{2+}\right] \mathrm{i}\right)$ in the presence of $1 \mathrm{mmol} / \mathrm{/} \mathrm{CaCl}$ or $5 \mathrm{mmol} / \mathrm{LGTA}$ in washed platelets from the control group ( $n=8$; open columns), the diabetic patients with increased platelet aggregation rates (DM-A) group ( $n=6$; dotted columns), and the diabetic patients with normal platelet aggregation rates (DM-B) group ( $n=7$; hatched columns). Increase in $\left[\mathrm{Ca}^{2+}\right] \mathrm{i}$ was calculated by subtracting the basal $\left[\mathrm{Ca}^{2+}\right]$ i from the maximal $\left[\mathrm{Ca}^{2+}\right] \mathrm{i}$ induced by PAF. All experiments were performed in duplicate. Values are mean \pm SEM. $" p<0.05$

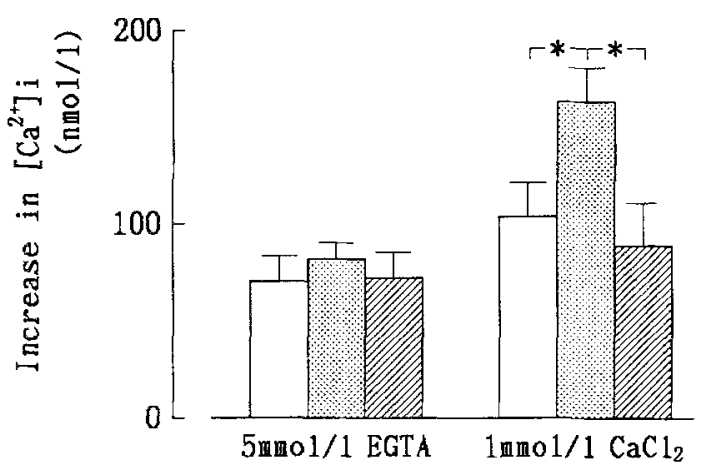

Fig.4. A23187-induced increase in intracellular free calcium concentrations $\left(\left[\mathrm{Ca}^{2+}\right] \mathrm{i}\right)$ in the presence of $1 \mathrm{mmol} / 1 \mathrm{CaCl}_{2}$ or $5 \mathrm{mmol} / \mathrm{l} \mathrm{EG}$ TA in washed platelets from the control group ( $n=8$; open columns), the diabetic patients with increased platelet aggregation rates (DM-A) group ( $n=6$; dotted columns), and the diabetic patients with notmal platelet aggregation rates (DM-B) group $(n=7$; hatched columns). Increase in $\left[\mathrm{Ca}^{2+}\right] \mathrm{i}$ was calculated by subtracting the basal $\left[\mathrm{Ca}^{2-}\right]$ i from the maximal $\left[\mathrm{Ca}^{2+}\right]$ i induced by A23187. All experiments were performed in duplicate. Values are means \pm SEM. * $p<0.05$

lular calcium to exclude calcium influx from the extracelIular space. These observations suggest that calcium release from intracellular calcium pools may be enhanced in the DM-A group. Both thrombin and PAF induce phosphoinositide breakdown to produce inositol 1, 4, 5-trisphosphate $[12,17]$, which causes calcium release from intracellular pools [13]. Our recent study [14] indicated that thrombin-induced phosphoinositide turnover is increased in platelets from Type 2 diabetic patients associated with enhanced platelet aggregation rates. From this evidence, the enhanced $\left[\mathrm{Ca}^{2+}\right] \mathrm{i}$ increase in the absence of extracellular calcium may be attributed to the increased phosphoinositide breakdown. An alternative mechanism is that calcium contents in intra-platelet calcium pools may be increased in the hyperfunctioning platelets in diabetes mel- litus. However, this seems unlikely, since, in the absence of extracellular calcium, there was no significant difference among the three groups in the $\left[\mathrm{Ca}^{2+}\right] \mathrm{i}$ increase induced by calcium ionophore A23187, which directly mobilizes calcium from intracellular pools [18] without provoking phosphoinositide breakdown [19].

Thrombin and PAF are known to cause calcium influx from the extracellular space [20-22]. In the presence of extracellular calcium, we demonstrated that thrombin and PAF induced a 2- to 3-fold increase in $\left[\mathrm{Ca}^{2+}\right] \mathrm{i}$ compared with those in the absence of extracellular calcium and that these $\left[\mathrm{Ca}^{2+}\right] \mathrm{i}$ increases were significantly enhanced in the DM-A group, suggesting that calcium influx may also be increased in platelets from the DM-A group. The detailed mechanisms behind calcium influx stimulated by thrombin or PAF are not fully understood. Recently, Zschauer et al. [23] reported the platelet calcium channel activated by thrombin stimulation. The increased calcium influx in the DM-A group may be due to increased activation of the calcium channel. We also showed that A23187 induced significantly greater $\left[\mathrm{Ca}^{2+}\right]$ increase in the presence of extracellular calcium in the DM-A group. However, it is not likely that A23187-induced calcium influx was enhanced, because A23187 causes calcium influx through permeabilizing platelets, not by opening the calcium channel. The mechanism of the enhanced $\left[\mathrm{Ca}^{2+}\right] \mathrm{i}$ increase evoked by $\mathrm{A} 23187$ in the presence of extracellular calcium remains to be determined.

Previous studies $[2,24]$ have shown that platelet aggregability is positively correlated with fasting blood glucose levels. We have also reported a significant correlation between platelet phosphoinositide breakdown induced by thrombin and fasting blood glucose levels [14]. However, in the present study, we could not find any significant differences between the $\left[\mathrm{Ca}^{2+}\right] \mathrm{i}$ increase and the fasting blood glucose levels or other epidemiological factors. The enhanced platelet $\left[\mathrm{Ca}^{2+}\right] \mathrm{i}$ increase in the DM-A group may be due to the original abnormalities in platelets themselves rather than to the effect of epidemiological factors. Further studies are needed to clarify the mechanisms of the abnormal platelet calcium mobilization in patients with diabetes mellitus.

In conclusion, thrombin and PAF caused significantly enhanced $\left[\mathrm{Ca}^{2+}\right] \mathrm{i}$ increase in platelets from Type 2 diabetic patients with increased platelet aggregation rates in both the presence and the absence of extracellular calcium. A23187-induced $\left[\mathrm{Ca}^{2+}\right]$ increase was also enhanced in these patients in the presence, but not the absence, of extracellular calcium. These results suggest that the increased intracellular calcium mobilization may be closely related to the enhanced platelet functions in diabetes mellitus and that this increased calcium mobilization may be due to the increased calcium release and influx.

\section{References}

1. Eldor A, Merin S, Bar-On H (1978) The effect of streptozotocin diabetes on platelet function in rats. Thromb Res 13: 703-714 
2. Halushka PV, Rogers RC, Loadholt CB, Colwell JA (1981) Increased platelet thromboxane synthesis in diabetes mellitus. I Lab Clin Med 97:87-96

3. Colwell JA, Winocour PD, Lopes-Virella M, Halushka PV (1983) New concepts about the pathogenesis of atherosclerosis in diabetes mellitus. Am J Med 30:67-80

4. Watanabe J, Umeda F, Wakasugi H, Ibayashi H (1984) Effect of vitamin $E$ on platelet aggregation in diabetes mellitus. Thromb Haemostas 51:313-316

5. Greco NJ, Arnold JH, O'Dorisio TM, Cataland S, Panganamala RV (1985) Action of platelet-activating factor on type 1 diabetic human platelets. J Lab Clin Med 105:410 416

6. Le Breton GC, Dinerstein RJ, Roth LJ, Feinberg H (1976) Direct evidence for intracellular divalent cation redistribution associated with platelet shape change. Biochem Biophys Res Commun 71: 362-370

7. Rink TJ, Smith SW, Tsien RY (1982) Cytoplasmic free $\mathrm{Ca}^{2+}$ in human platelets: $\mathrm{Ca}^{2+}$ thresholds and $\mathrm{Ca}$-independent activation for shape-change and secretion. FEBS Lett 148:21-26

8. Ware JA, Johnson PC, Smith M, Salzman EW (1986) Effect of common agonists on cytoplasmic ionized calcium concentration in platelets. J Clin Invest 77: 878-886

9. Knight DE, Scrutton MC (1980) Direct evidence for a role for $\mathrm{Ca}^{2+}$ in amine storage granule secretion by human platelets. Thromb Res 20: 437-446

10. Feinstein MB (1980) Release of intracellular membrane-bound calcium precedes the onset of stimulus-induced exocytosis in platelets. Biochem Biophys Res Commun 93: 593-600

11. Lapetina EG, Chandrabose KA, Cuatrecasas P (1978) Ionophore A23187- and thrombin-induced platelet aggregation: independence from cycloxygenase products. Proc Natl Acad Sci USA 75: 818-822

12. Watson SP, McConnell RT, Lapetina EG (1984) The rapid formation of inositol phosphates in human platelets by thrombin is inhibited by prostacyclin. J Biol Chem 259: 13199-13203

13. Brass LF, Joseph SK (1985) A role for inositol triphosphate in intracellular $\mathrm{Ca}^{2+}$ mobilization and granule secretion in platelets. $J$ Biol Chem 260: 15172-15179

14. Ishii H, Umeda F, Hashimoto T, Nawata $H$ (1990) Changes in phosphoinositide turnover, $\mathrm{Ca}^{2+}$ mobilization, and protein phosphorylation in platelets from NIDDM. Diabetes 39: 1561-1568

15. Born GVR (1962) Aggregation of blood platelets by adenosine diphosphate and its reversal. Nature 194: 927-929
16. Grynkiewicz G, Poenie M, Tsien RY (1985) A new generation of $\mathrm{Ca}^{2+}$ indicators with greatly improved fluorescence properties. $\mathrm{J}$ Biol Chem 260: 3440-3450

17. Billah MM, Lapetina EG (1983) Platelet-activating factor stimulates metabolism of phosphoinositides in horse platelets: possible relationship to $\mathrm{Ca}^{2+}$ mobilization during stimulation. Proc Natl Acad Sci USA 80: 965-968

18. Menashi S, Authi KS, Carey F, Crawford N (1984) Characterization of the calcium-sequestering process associated with human platelet intracellular membranes isolated by free-flow electrophoresis. Biochem J 222: 413-417

19. Moscat J, Moreno F, Iglesias S, Garcia-Barreno P, Municio AM (1986) Ionophore A23187 induces a refractory state in thrombinactivated release of inositol phosphates. Biochem J 238: 709-714

20. Lee T, Malone B, Blank ML, Snyder F (1981) 1-Alkyl-2-acetyl$s n$-glycero-3-phosphocholine (platelet-activating factor) stimulates calcium influx in rabbit platelets. Biochem Biophys Res Commun 102: 1262-1268

21. Clare KA, Scrutton MC (1984) The role of $\mathrm{Ca}^{2+}$ uptake in the response of human platelets to adrenaline and to 1-O-alkyl-2acetyl-sn-glycero-3-phosphocholine (platelet-activating factor). Eur J Biochem 140: 129-136

22. Doyle VM, Rüegg UT (1985) Lack of evidence for voltage dependent calcium channels on platelets. Biochem Biophys Res Commun 127: 161-167

23. Zschauer A, Breemen C van, Bühler FR, Nelson MT (1988) Calcium channels in thrombin-activated human platelet membrane. Nature 334: 703-705

24. Jones DB, Davis TME, Bown E, Carter RD, Mann JI, Prescott RJ (1986) Determinants of ADP-induced platelet aggregation in diabetes mellitus. Diabetologia 29: 291-294

Received: 14 August 1990

and in revised form: 26 November 1990

Dr. H. Ishii

3rd Department of Internal Medicine

Faculty of Medicine

Kyushu University

3-1-1 Maidashi, Higashi-ku, Fukuoka 812

Japan 